\title{
La índole espiritual de la reforma del clero en san Juan de Ávila
}

\author{
The Spiritual Nature of the Reform of the Clergy \\ in Saint John of Avila
}

\section{MARÍA JESÚS FERNÁNDEZ CORDERO}

Universidad Pontificia Comillas

ORCID: https://orcid.org/0000-0002-3375-3231 | mjfcordero@comillas.edu

Fecha de recepción: 26/6/2021

Fecha de aceptación: 20/7/2021

https://doi.org/10.52039/seminarios.v66i228.442

RESUMEN: La reforma del clero que san Juan de Ávila planteó debe entenderse como una recuperación de la naturaleza pastoral de los ministerios en la Iglesia. En este sentido, requería una vuelta al ejercicio de los actos espirituales que los definen como participación existencial en el sacerdocio y el pastoreo de Jesucristo. Este artículo no trata de sintetizar sus propuestas, sino de poner de relieve este aspecto más interior y espiritual, que supuso una fuerte llamada a la conversión. Esta interioridad es la que genera los cambios en lo exterior, en las leyes y en las estructuras, para una renovación verdadera.

PALABRAS CLAVE: Memoriales al concilio de Trento, oficio sacerdotal, obispos, formación sacerdotal

ABSTRACT: The reform of the clergy that Saint John of Avila proposed must be understood as a recovery of the pastoral nature of the ministries in the Church. In this sense, it required a return to the exercise of the spiritual acts that define them as existential participation in the priesthood and the shepherding of Jesus Christ. This article does not try to synthesize his approaches, but rather to highlight this more interior and spiritual aspect, which was a strong call to conversion. This interiority is what generates the changes in the exterior, in the laws and in the structures, for a true renewal.

KEYwords: Memorials to the Council of Trent, priestly office, bishops, priestly formation

\section{INTRODUCCIÓN}

«No se sabe de ninguna reforma un poco seria en la Iglesia que haya dejado de llevar consigo una revisión de la enseñanza de los clérigos, una reanimación, una vuelta a las fuentes, a las zonas más profundas de la tra- 
dición» ${ }^{1}$. Estas palabras de Yves Congar, pertenecientes a su obra ya clásica sobre la reforma en la Iglesia (1950), iban acompañadas de una nota a pie de página en la que mencionaba algunos ejemplos, entre ellos Juan de Ávila. Aunque el conocimiento que el dominico francés tenía de nuestro autor era indirecto ${ }^{2}$, no deja de resultar significativo que lo eligiera para ilustrar esta afirmación ${ }^{3}$. Ciertamente, todos estos aspectos caracterizaron la vida y la obra de Ávila. Del mismo modo, podríamos también descubrir en él las cuatro condiciones de una reforma sin cisma que expuso magistralmente Congar: la primacía de la caridad y del sentido pastoral, la permanencia en la comunión del todo, la paciencia y el retorno al principio de la tradición. El Maestro Ávila cumplió ampliamente tales requerimientos, en unos tiempos llenos de creatividad y a la vez convulsos.

Sus grandes líneas de reforma han sido expuestas en numerosos trabajos ${ }^{4}$. Por mi parte, en las páginas que siguen me propongo simplemente poner de relieve la índole o naturaleza espiritual que las cualifica, con el objetivo de que el lector pueda percibir claramente que su movimiento renovador no fue mero sistema de ideas, exigencia disciplinar, cambio superficial o proyección utópica.

1. Y. Congar, Verdadera y falsa reforma en la Iglesia, Salamanca 2014, 161.

2. Congar remitía al artículo de A. Duval, «Quelques idées du bienheureux Jean d'Avila sur le ministère pastoral et la formation du clergé», La Vie Spirituelle. Supplément (1948) 121-153, el cual se hacía eco de los trabajos de edición de obras inéditas y estudios por parte de C. M. Abad, R. S. de Lamadrid y L. Sala Balust: «On assiste en ce moment en Espagne à un renouveau complet des études aviliennes» $(121, \mathrm{n} .1)$.

3. Aunque de modo discreto, lo citó en total cuatro veces en su obra: en la ya mencionada; al hablar del esfuerzo renovador pastoral por vía de santidad, aludiendo a su trabajo misionero (Y. Congar, Verdadera ..., 217); al vincular la eficacia del concilio de Trento a la práctica de corrientes espirituales anteriores y posteriores (236); y al hablar de la paciencia (una de las cuatro condiciones para una reforma sin cisma), mencionando su paso por la cárcel del Santo Oficio (271). Esto indica que percibió el sentido del esfuerzo renovador avilista y lo encuadró bien en su interpretación de las reformas del siglo XVI.

4. Entre lo publicado en este siglo, J. I. Tellechea Idígoras, «San Juan de Ávila y la reforma de la Iglesia», en: El Maestro Ávila. Actas del Congreso Internacional, Madrid 27-30 noviembre 2000, Madrid 2002, 47-75; S. López Santidrián, «Reformador», en: M. E. González Rodríguez (ed.), San Juan de Ávila, doctor: magisterio vivo, Madrid 2013, 57-100; M. Navarro Sorní, «San Juan de Ávila y la reforma de la Iglesia», en: N. Álvarez de las Asturias (ed.), San Juan de Ávila, Doctor de la Iglesia, Madrid 2013, 49-84; M. J. Fernández Cordero, Juan de Ávila (1499?-1569). Tiempo, vida y espiritualidad, Madrid 2017, 459-539; A. Fernández Collado, «San Juan de Ávila y la reforma del clero. Memoriales y advertencias a los concilios de Trento y provincial de Toledo», Scripta Fulgentina 57-58 (2019) 283-295; J. R. Godino Alarcón, «El marco histórico del ministerio presbiteral en el siglo XVI y la reforma de la Iglesia en los Memoriales de Ávila», en: F. J. Martínez Rojas (coord.), El presbitero secular en el siglo XXI a la luz del magisterio de San Juan de Ávila. Actas del Congreso Internacional, Jaén 2020, 89-102. 
Ya hace tiempo que los estudiosos han indicado, de distintas maneras, esta naturaleza espiritual de la obra reformadora avilista. Jesús Navarro habló de «unas directrices sobrenaturales de reforma», por cuanto provienen de la naturaleza misma de la Iglesia, y de una «interioridad» en ellas con insistencia en la caridad ${ }^{5}$. Álvaro Huerga reiteró que «la perspectiva sobrenatural domina su pensamiento de reforma» y que el valor y actualidad de su mensaje brota «de su enfoque teológico de los problemas, de su riqueza experimental y de sus equilibradas, casi intuitivas, soluciones ${ }^{6}$. Tellechea advirtió que en sus Memoriales había «un dinamismo nacido del seno mismo de la Iglesia y apoyado en su mejor tradición» ${ }^{7}$. Juan del Río, al estudiar su eclesiología, en la que la Iglesia es fruto del amor trinitario, subrayó el papel del Espíritu Santo en ella como impulsor de su constante renovación y entendió desde aquí «la valentía que le movía para hablar de la reforma de la Iglesia en todos sus estamentos» ${ }^{8}$. Navarro Sorní afirma que «su reforma tiene una raíz teológica» y busca «actuar la imagen de Iglesia y del ministerio que extrae de la Sagrada Escritura y de la Tradición viva» ${ }^{9}$.

Pues bien, ¿qué tipo de mirada a la Iglesia hizo de Juan de Ávila un verdadero reformador? ¿Por qué enfocó gran parte de sus esfuerzos a la reforma del clero? ¿Qué tipo de reforma propuso? A estos interrogantes intentamos responder en estas páginas.

\section{UNA MIRADA CRISTIANA Y SACERDOTAL AL PUEBLO DE DIOS}

En su reflexión sobre el papel del profetismo y del reformismo en la Iglesia, Congar señalaba que el profeta lleva en sí «el conocimiento de las cosas de Dios y el sentido de su voluntad», y el reformador tiene la función «de juzgar el tiempo y las cosas que existen en el tiempo a la luz de su verdad con relación a lo Absoluto y a la meta hacia la que caminan ${ }^{10}$. En Juan de Ávila, ambas dimensiones tienen que ver con el tipo de mirada que cultivó en su experiencia espiritual. Ciertamente, su aportación debe situarse en su contex-

5. J. Navarro, La reforma de la Iglesia en los escritos del Maestro Ávila. Su enfoque teológico, Granada 1964, 356.

6. A. Huerga, «La reforma de la 'Santa Madre Iglesia' según el Maestro Juan de Ávila», Communio 3 (1970) 175-225; las citas en 220 y 219.

7. J. I. Tellechea, «San Juan de Ávila...», 73.

8. J. del Río Martín, Santidad y pecado en la Iglesia. Hacia una eclesiología de San Juan de Ávila, Madrid 2015, 390.

9. M. Navarro Sorní, «San Juan de Ávila...», 60.

10. Y. Congar, Verdadera ..., 187-188. 
to, tanto por lo que se refiere a la crítica hacia el estamento eclesiástico -con una tradición literaria importante en el ámbito hispano desde el siglo XV-, como por su inserción en la reforma española previa al concilio de Trento ${ }^{11}$, modulada en su caso por su origen converso, su formación teológica en la Universidad de Alcalá y el eclecticismo con que se desenvolvió respecto a las distintas escuelas teológicas y corrientes espirituales. Pero nos interesa ahora resaltar que ese conocimiento profético y juicio reformador surgen en él del modo de mirar la realidad.

El Memorial segundo al concilio de Trento ${ }^{12}$, que lleva por título Causas y remedios de las herejías, comienza con estas palabras:

Los lastimeros males que en nuestros tiempos han venido sobre nuestro pueblo cristiano, es mucha razón que despierten nuestro profundo y peligroso adormecimiento que del servicio de nuestro Señor y del bien general de la Iglesia y de nuestra particular salvación todos o casi todos tenemos, para que con ojos abiertos sepamos considerar la grandeza del mal que nos ha venido y el peligro que nos amenaza y pongamos remedio, con el favor divinal, en lo que tanto nos cumple.

Está claro que se trata de una mirada desde dentro, solidaria, que no se autoexcluye en la situación que denuncia. El texto que sigue, sobre cómo Dios manifiesta sus juicios para que recuperemos «el sentido de lo espiritual», sitúa su reflexión en el plano de la historia de Dios con su pueblo. Se trata, por consiguiente, de mirar las cosas en relación con la historia de la salvación. Los males, entonces, adquieren la dimensión del pecado y los ojos abiertos se identifican con la mirada de fe capaz de percibir lo que separa de Dios. Ávila utilizó en numerosas ocasiones la asociación clásica y bíblica entre pecado, oscuridad y sueño. Hablando de los pecadores, dice en otro lugar: «En muchas otras partes los pinta el Espíritu Santo dormidos, metidos en tinieblas y cerrados los ojos, como gente que no acaba de ver ni conocer la miseria que los cerca» ${ }^{13}$.

11. Remitimos al panorama historiográfico que aporta R. M. Pérez García, «El tema de la crítica al clero en la obra de Francisco de Osuna en el contexto del pensamiento católico reformista pretridentino», en: E. Soria Mesa - A. J. Díaz Rodríguez (eds.), Iglesia, poder y fortuna. Clero y movilidad social en la España moderna, Granada 2012, 139-189.

12. En adelante: Memorial II, n. 1, en: San Juan de Ávila, Obras completas, Madrid 2001, vol. II, 521-619. Citaremos por esta edición, Madrid 2000-2003, en cuatro volúmenes, con la abreviatura OC seguida del volumen en números latinos. Sobre la escritura de estos Memoriales que envió al arzobispo de Granada Pedro Guerrero para su asistencia a Trento, M. J. Fernández Cordero, Juan de Ávila ..., 323-328.

13. Lecciones sobre la epístola a los Gálatas, c. III, n. 28, OC II, 60. 
Estas claves nos permiten comprender que la mirada avilista que guía los escritos de reforma puede y debe relacionarse con esta temática en el conjunto de su obra. Ya en el Audi, filia enseñaba a tener un orden en el mirar: primero a uno mismo, después a Dios y después al prójimo ${ }^{14}$. De este modo, el propio conocimiento, con su doble sentido de conciencia de nuestra "poquedad» y de reconocimiento de nuestro ser como «dádiva de Dios», se articulaba con el conocimiento de Dios, centrado en el conocimiento de Jesucristo y en la meditación de su pasión, de tal modo que la mirada al prójimo quedaba filtrada y purificada por las dos miradas anteriores: «aquel mira bien a sus prójimos, que los mira con ojos que pasen por sí mismo y que pasen por Cristo» ${ }^{15}$. Lo primero, mirar al prójimo habiéndose mirado uno mismo, es la mirada verdaderamente humana: quien no la practica, «no mira a los hombres con ojos humanos, que deben ser piadosos», sino que cae en la falta de compasión, de paciencia y de caridad. Lo segundo cualifica esta mirada humana como cristiana y conlleva un proceso de configuración con Cristo:

... y así como mirándoos a vos, mirastes a los prójimos con ojos humanos, así, mirando a Cristo, los miraréis con ojos cristianos, quiero decir, con los ojos que Él los miró. Porque, si Cristo en vos mora, sentiréis de ellos como Él sintió, y veréis con cuánta razón sois vos obligada a sufrir y amar a los prójimos, a los cuales Él amó y estimó como la cabeza ama a su cuerpo, y el esposo ama a su esposa, y como hermano a hermanos, y como amoroso padre a sus hijos ${ }^{16}$.

No perdamos de vista el lenguaje esponsal y la simbología del cuerpo de Cristo, algo muy característico de su teología y eclesiología ${ }^{17}$. Es esta mirada cristificada la que trastoca los valores mundanos y genera un amor nuevo que nos vincula con el prójimo:

No se puede escribir ni decir el amor que se engendra en el corazón del cristiano que mira a sus prójimos, no según lo de fuera, así como según riquezas, linaje o parentesco, o otras condiciones semejables, mas como unos entrañables pedazos del Cuerpo de Jesucristo, y como cosa conjuntísima a Cristo, con todo linaje de parentesco y amistad ${ }^{18}$.

14. Audi, filia [1], II, n. 7, OC I, 440 ss.

15. Ibid., II, n. 65, OC I, 472.

16. Ibid., II, n. 66, OC I, 473.

17. R. Aldana Valenzuela, «La reforma de la Iglesia en la escucha de la Palabra de Dios. Una mirada al magisterio de San Juan de Ávila», Studia Cordubensia 6 (2013) 5-144.

18. Audi, filia [1], II, n. 66, OC I, 473. 
Volviendo al comienzo del Memorial segundo, cuando estos ojos contemplan los males que afectan al pueblo cristiano se asemejan a los del profeta Jeremías, que «mucho lloró por ver su ciudad destruida», o a los de Isaías, que lloró por la destrucción de su pueblo y se conturbó por la suerte del de Babilonia ${ }^{19}$.

Si la mirada profética capta el sentido de la historia en la relación de la humanidad con Dios y la cristiana se caracteriza por un amor como el de Cristo (Jn 15,12), la mirada sacerdotal se nutre de la contemplación del misterio de la redención. Los ojos que penetran en este misterio descubren que brota de la mirada del Hijo hacia el corazón y la voluntad del Padre, y de la mirada del Padre hacia la pasión del Hijo, el lugar en que culmina la obediencia del Hijo y el perdón del Padre para nosotros en Cristo ${ }^{20}$. Si el cristiano ha de mirar hacia aquí para hacerse partícipe subjetivamente de este misterio, quien tiene oficio sacerdotal lo hará además para imitar a Cristo en su oración y en su ofrenda (sacrificio), de modo que, en su acción sacramental, concuerden su representación externa de Cristo (en la misa) y su conformación interior (en los deseos, la oración y el ofrecimiento de sí mismo por sí y por el mundo ${ }^{21}$.

Podríamos hablar también de una mirada pastoral, teniendo en cuenta que el lenguaje avilista sobre los ministerios se enmarca en la distinción vigente desde los tiempos medievales entre orden y jurisdicción, y que la unidad entre lo sacerdotal y lo pastoral radica en la única ofrenda redentora de Cristo, Sacerdote y Pastor ${ }^{22}$. El cuidado del cuerpo místico de Cristo, por medio de los ministerios pastorales (cura de ánimas, confesor, predicador), requiere «no menor santidad que para ofrecer el santo sacrificio del altar» ${ }^{23}$.

Son, pues, estas miradas las que permiten comprender cómo se situaba Ávila ante los males que aquejaban a la Iglesia de su tiempo. Por eso su crítica en los escritos de reforma es tan penetrante y, a la vez, resulta tan pura: «tiene esa grandeza de alma de los grandes teólogos de la patrística que le permite mirar de frente la condición de la Iglesia, que es santa solo en el acto de ser purificada por su Señor» ${ }^{24}$.

19. Memorial II, n. 2, OC II, 522.

20. Expuso esta doctrina en el Tratado del amor de Dios, OC I, 951-974; M. J. Fernández Cordero, Juan de Ávila..., 669-688.

21. Tratado sobre el sacerdocio, OC I, 907-946; M. J. Fernández Cordero, Juan de Ávila ..., 800-822.

22. M. J. Fernández Cordero, «Jesucristo, 'fuente de nuestro sacerdocio'. Claves para la comprensión del pensamiento de Juan de Ávila sobre el ministerio sacerdotal», Studia Cordubensia 11 (2018) 5-24.

23. Tratado sobre el sacerdocio, n. 37, OC I, 939.

24. R. Aldana Valenzuela, «La reforma de la Iglesia...», 37. 


\section{LA REFORMA DE LOS MINISTROS: CONVERSIÓN AL SENTIDO PASTORAL}

El Memorial primero al concilio de Trento, que lleva por título Reformación del estado eclesiástico ${ }^{25}$, partía de la constatación de que «lo que este santo concilio pretende es el bien y la reformación de la Iglesia», y Ávila lo escribió desde este convencimiento:

Y para este fin, también consta que el remedio es la reformación de los ministros de ella. Y como este sea el medio de este bien que se pretende, se sigue que todo el negocio de este santo concilio ha de ser dar orden cómo estos ministros sean tales como oficio tan alto requiere ${ }^{26}$.

Si bien esta convicción habría que resituarla hoy eclesiológicamente ${ }^{27}$, en su raíz concuerda con lo que se ha llamado «eclesiología implícita» del concilio de Trento: la salus animarum, que guio su obra reformadora ${ }^{28}$. Podríamos decir que esta perspectiva es la que genera las sinergias profundas entre la experiencia y la obra avilistas y las orientaciones del concilio, pues se trataba de recuperar la dimensión pastoral de la Iglesia ${ }^{29} \mathrm{y}$, en esta línea, el sentido pastoral de sus ministros.

En su diagnóstico de los males de la Iglesia, Ávila denunció, en los pastores negligentes, carencias muy radicales:

Mas ¿por qué se les pide a estos pastores lo que no tienen? ¿Cómo ejercitarán oficios de médicos, pues nunca aprendieron el arte? ¿Cómo aprenderán lo que

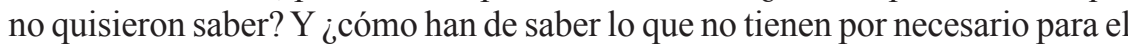
buen uso de su oficio? $\mathrm{O}$, si les parece que esta arte de curar ovejas es de algún provecho, estiman en tan poco a ellas y a él, que el alteza de ellos no se quiere inclinar a ejercitar cosa tan baja; ni el regalo de ellos sufre los trabajos que son menester para curar llagas feas de mirar y penosas para oler, y para tomar en los hombros las ovejas perdidas, y llorar y orar de noche por ellas, pidiendo pasto al Señor con que provechosamente las apacienten de día: sufrir al tentado, esforzar

25. En adelante, Memorial I, OC II, 485-514.

26. Ibíd., n. 9, OC II, 489-490.

27. K. Schatz, Los concilios ecuménicos. Encrucijadas en la historia de la Iglesia, Madrid 1999, 201, reconoce que esta concepción de la reforma «primero del clero, y después del pueblo» es «cosa que suena mal desde nuestra perspectiva pastoral actual», pero señala que se trataba «de una cura pastoral más intensa y de una interiorización pastoral». A. Antón, $E l$ misterio de la Iglesia. Evolución histórica de las ideas eclesiológicas, Madrid 1986, vol. I, 751, advierte que Trento no presentó una eclesiología sistemática, orgánica, completa, ni en sus decretos doctrinales ni en los de reforma.

28. Id. A. Antón toma de G. Alberigo esta idea de la salus animarum como una eclesiología implícita y sobre todo práctica, siendo una fórmula de la época, y la considera «el principio y fundamento» de la obra reformadora tridentina.

29. A. Fernández Collado, «San Juan de Ávila y la reforma del clero...», 286. 
el escrupuloso, dar vivos ejemplos de perfecta virtud, abajarse a comunicar con los pobres, hacerse siervo del pueblo por Dios, y otros semejantes trabajos que los buenos perlados tienen por honra y descanso, y los malos huyen de ellos con todas sus fuerzas. Y así, olvidando, como San Gregorio dice, «qui sunt prelati causa animarum», han dejado esto, que era proprio oficio suyo y muy íntimo, y hanse contentado con sólo ejercicio de regimiento de cosas exteriores, que ni parece que perjudican tanto a la honra vana que buscan ni tienen aquellos trabajos anejos que tiene la cura de ánimas, y tiran más a enseñorear y mandar que a administrar y tener corazón y obras de padres ${ }^{30}$.

Esto significa que la reforma implicaba un verdadero cambio de mentalidad: el paso de una concepción del ministerio imbuida de los valores de la sociedad estamental (jerarquización social, poder/dominio, honra, apariencia, comodidad) a otra conforme a la naturaleza pastoral del mismo, a su identidad y su función en la Iglesia. Su reflexión apunta a esto para todos los niveles de la jerarquía eclesiástica, para toda función ministerial y para las estructuras.

\section{a) El papa, supremo pastor: vivir vida de cruz}

Para Ávila, la reforma del papado ${ }^{31}$ consistía también en esto: mortificar honra, codicia y placeres, con una alusión específica al nepotismo - «hijos, hermanos, amigos, parientes»-y al uso del poder, en el que no ha de buscar intereses propios, sino la honra de Dios y el bien de la Iglesia. Pero no enfocaba esto sólo como reforma de costumbres, aunque la incluía, sino como ejercicio sacerdotal del vicario de Cristo, cuyo dolor por la Iglesia debe ser entrañable (término que en Ávila tiene inspiración bíblica ${ }^{32}$ ) y cuya ofrenda personal debe llevarle a asumir la cruz (incluido el martirio) y la mortificación.

Ábranse sus entrañas, y sean comidas con el santo celo de la casa de Dios que le está encomendada, para sentir sus caídas y para ofrecerse, si menester fuere, a muerte de cruz, a semejanza de aquel Señor cuyo vicario es, y de San Pedro, su primer antecesor, y a todo lo que menester fuere para remedio y reformación de la Iglesia ${ }^{33}$.

Llegaba a pensar que, si el papa asumía este espíritu, se desharían los argumentos de los herejes, que justificaban la división por los malos ejem-

30. Memorial II, n. 10, OC II, 330.

31. Ávila se refería siempre al pontífice por su ministerio, nunca por la persona que ocupaba la sede papal. Sus palabras en el Memorial II se corresponden con el pontificado de Pío IV.

32. R. Aldana Valenzuela, «La reforma de la Iglesia...», 14-18.

33. Memorial II, n. 41, OC II, 565-566. 
plos de la sede romana, y se generaría un movimiento de esta misma índole espiritual en el pueblo de Dios: «nacerán innumerables corazones, que se ofrecerán a Dios, tras él y con él, mortificados a sí mismos y vivos a Dios». Y este sería también el dinamismo en el clero: «¿Quién de los eclesiásticos osará vivir como quiere viendo a su príncipe vivir vida de cruz por el bien de la Iglesia?» ${ }^{34}$.

\section{b) Los obispos: al modo de Cristo, enviado del Padre}

Como hemos visto en la denuncia avilista de los pastores negligentes, la reforma de los obispos debía consistir en recuperar lo que era propio de su ministerio. Esto significaba ejercer el pastoreo por sí mismos y, junto con ello, redescubrir su interioridad: pasar del «regimiento de cosas exteriores» y de «enseñorear y mandar» a «administrar y tener corazón y obras de padres $\rangle^{35}$.

En las Advertencias al concilio de Toledo $(1565)^{36}$, ya en la etapa de aplicación del concilio de Trento, los aspectos exteriores no se reforman por mera disciplina, sino por el sentido interior que ha de animarlos, por la espiritualidad que ha de caracterizar a los obispos. Así, ellos tienen «el oficio de Moisés», de «subir al monte y hablar con Dios»; de ese encuentro, con el resplandor en el rostro y las tablas de la ley en la mano, debían luego «abajarse» para enseñar al pueblo. Este trato con Dios debía transformar su vida, su modo de estar en la sociedad y de ejercer su ministerio:

Y, si hiciesen esto de subir al monte a tractar con Dios, allí les enseñaría su Majestad que sus casas han de ser escuela de virtudes, donde vayan los ignorantes a aprenderla, y no tropiezo donde se pierda si se lleva alguna. Retrato de la escuela y colegio apostólico, y no de señores mundanos. La casa de los obispos, casa de cirujanos de almas ha de ser, donde se atreva [a] ir el desconsolado a pedir consuelo; el tentado, remedio para su tentación; el flaquito, remedio para su flaqueza; y que se atreva el más pobrecito y mendigo a ir a ella como a casa de su proprio padre. Finalmente, hecha una botica de todas medecinas; y el perlado, que sea tan sabio y ejercitado cirujano y tenga tan grande caridad para ejercitar la cirugía, que todos los enfermos que a él llegaren lleven sanidad de sus heridas ${ }^{37}$.

34. Ibid., 567.

35. Ibid., n.10, 530-531.

36. Sobre este concilio, A. Fernández Collado, Concilios Toledanos postridentinos. Estudio y edición, Toledo 1996; Id., «El Concilio Provincial Toledano de 1565», Anthologica Annua, 42 (1995) 425-613.

37. Advertencias al concilio de Toledo, n. 4, OC II, 649. 
Todo un estilo de vida, caracterizado por la presencia señorial y la magnificencia, se contrasta con el estilo de vida de Cristo. De ahí que el concilio provincial deba abordar «el modo de vivir de los obispos y reformación de casa ${ }^{38}$; sus recomendaciones son tan concretas como la austeridad en el ajuar (ni ropas ni tapicerías de seda, ni vajillas de plata) y la presencia de servidores (ni lacayos, pajes u otros oficios propios de las casas señoriales, sino sacerdotes virtuosos y gente que trate de virtud).

Ávila dio más importancia a la vida austera y a la dedicación plena al oficio pastoral que al deber de residencia de los obispos ${ }^{39}$. Y ello porque tampoco el cumplimiento meramente disciplinar de esta exigencia era garantía de verdadera reforma:

... la residencia, a la cual los obispos son tan obligados, no es solamente estar presentes como si fueran estatuas de madera, como es claro, sino ejercitar con su persona el ministerio episcopal, como es la predicación, confirmar los niños, «agnoscere oves nominatim», ser verdaderos padres de los pobres «et alia multa». Los cuales oficios no los puede ejercitar en todas sus ovejas estando en la ciudad; $\mathrm{y}$ tan ovejas son las otras como aquéllas, y aún más necesitadas, por no tener tales y tantos socorros, comúnmente, como los ciudadanos ${ }^{40}$.

Es este un ejemplo de cómo no se trata tanto de la aplicación de una ley, sino del sentido pastoral que ha de guiar la actuación del obispo.

Dos elementos son destacados en el ministerio episcopal. El primero, la predicación, que había sido definida por Trento como praecipuum episcoporum munus, el oficio principal de los obispos (sesión V, c. 2 de ref.). Ávila insistía en la necesidad de que éstos lo realizasen personalmente, y no sólo en la catedral, sino también recorriendo las parroquias y exponiendo al pueblo «una doctrina llana, que ésta es la que aprovecha más» ${ }^{41}$. El segundo, el cuidado de los pobres:

Hay gran necesidad que en los obispos se reforme el descuido grande que se tiene con los pobres, viudas, encarcelados, huérfanos y niños que exponen en la iglesia; porque todas estas cosas están puestas a su cargo, y tienen de llevarlas en sus hombros como verdadero padre de los dichos, a quien no una vez, sino millares de ellas, están encargados como cosa propria en los cánones de los concilios y en las doctrinas de los santos ${ }^{42}$.

38. Ibid., n. 7, 650 .

39. J. Navarro, La reforma ..., 210. M. J. Fernández Cordero, Juan de Ávila ..., 489-491.

40. Advertencias..., n. 20, OC II, 661.

41. Ibid., n. 17, 658.

42. Ibid., n. 24, 665. 
Ávila enfocaba las actuaciones del obispo en relación con los pobres -lo que tocaba a la administración de sus rentas, a los diáconos según el modelo de la Iglesia primitiva, a la promoción de cofradías específicas para proporcionar remedio- como provenientes de su responsabilidad pastoral: puesto que la pobreza es origen de otros muchos males que afectan a los pobres también en su relación con Dios, el obispo se ha de situar ante ellos «como verdadero padre de estas almas, y el remedio es proveerles la necesidad, pues ella es la raíz de todo el daño» ${ }^{43}$.

De igual modo, la visita pastoral tiene el sentido de alentar a todos en la virtud, desde el buen ejemplo, y ver «con los ojos las necesidades espirituales y temporales, y así se moverá más el corazón para remediarlas, y otras muchas cosas se hacen y remedian ${ }^{44}$. Y la frecuencia de sínodos es comparada a la tarea de cavar pozos para «hallar el agua viva de vera reformación y observancia»: así como Isaac cavó pozos en la vaguada de Guerar, y aunque varios quedaron cegados por las disputas con los pastores de esa tierra, finalmente en uno de ellos se logró el agua necesaria (Gén 26, 17-22), así parece que el realismo con que Ávila contemplaba las dificultades de los sínodos no le impedía considerar que su realización frecuente (reiterando una y otra vez los esfuerzos) era un cauce esencial para cultivar la viña del Señor ${ }^{45}$.

Uno de los escritos en que mejor se puede percibir el espíritu que Juan de Ávila intentaba despertar y alentar en los obispos es la Carta 182, dirigida a don Cristóbal de Rojas y Sandoval, por entonces obispo de Córdoba, precisamente con ocasión de la celebración del concilio provincial de Toledo que acabamos de mencionar y que a él le correspondió presidir al estar preso el arzobispo Fr. Bartolomé Carranza ${ }^{46}$; las orientaciones avilistas se cargaban de sentido profético y buscaban suscitar en el destinatario una libertad evangélica que debía provenir de la esencia del ministerio episcopal.

Ávila le manifiesta a Rojas y Sandoval su alegría por el encargo que éste ha recibido, pues piensa que «ha de ser causa de gran reformación en los obispos y obispados del reino», y le invita a mirarlo «con ojos cristianos», entendiendo que es Dios mismo quien se lo ha confiado ${ }^{47}$. Por este motivo, su disposición ha de consistir en «quitar de sí todos los impedimentos a la inspiración del Señor y a las obras que Él por medio de vuestra señoría qui-

43. Ibid., n. 26, 668.

44. Ibid., n. 20, 661.

45. Ibid., 21-23, 663-665.

46. M. J. Fernández Cordero, Juan de Ávila ..., 334-346.

47. Carta 182, OC IV, 601. 
siere obrar» ${ }^{48}$. Para Ávila, la presencia del obispo de Córdoba en este concilio como presidente constituía una «embajada de parte de Dios», una misión concreta ante los obispos más principales del reino, en la que era importante no llevar gloria mundana, sino «gloria conforme a la del Señor». En esta línea, el núcleo de la carta es el siguiente:

Mire vuestra señoría que tal vino [Cristo] cuando el Padre le envió por embajador al mundo a anunciar su voluntad y a sacarlo de sus malos caminos y meterlo en los de Dios. Cierto es que nació en pobreza y aspereza, y de la misma manera vivió, y con crecimiento de esto murió. Y habiendo Él traído la embajada del Padre con este tan humilde aparato, no se agradará que su embajador, pues es de rey celestial, vaya con aparato de mundo. [...] No piense vuestra señoría persuadir a nadie reformación, si él [vuestra señoría] no va reformado. Ni piense que por otros medios ha de ser su embajada provechosa, sino por los que Jesucristo por ordenación de su Padre tomó para cumplir la suya. [...] gran temeridad es querer el siervo y criado huir de los medios que tomó el Hijo y tener en más la propria y carnal sabiduría que la de Dios. Alce los ojos vuestra señoría al Hijo de Dios puesto en una cruz, desnudo y crucificado, y procure desnudarse del mundo y de la carne, y sangre, codicia, y de honra, y de sí mismo, para que así sea todo él semejante a Jesucristo y sea su embajada eficaz y fructuosa. Muera a todo y vivirá a Dios, y será causa para que otros vivan, porque, si esto no lo hace, perderse ha a sí y a los otros, pues la palabra de Cristo Señor nuestro no puede faltar: Nisi granum frumenti, etc. $\left(\right.$ Jn 12,24) ${ }^{49}$.

La reforma que había de llegar al clero y a las ovejas debía comenzar por los obispos, y su inicio era un acto espiritual de muerte a uno mismo y todo lo mundano para realizar la misión desde la configuración con Cristo y con los medios que él escogió. Hay de fondo una teología del envío que ilumina el ministerio episcopal y todo ministerio pastoral.

\section{c) Clero catedralicio: vida estrecha de comunidad}

El clero catedralicio es el que recibe las críticas más duras de los escritos de reforma avilistas. Así, en el Memorial primero denuncia:

Cerca de la vida de dignidades, canónigos y racioneros, cosa conocida es a todos que la fábula del mundo, y el terrero de los legos, y el escándalo común de la Iglesia son ellos; pues, por la mayor parte, ni predican, ni leen, ni confiesan, ni aun dicen misa casi en todo el año; y muchos viven con deshonestísima compañía, sin que nadie sea parte para podérsela quitar. Y algunos son tan desvergonzados, que en trajes profanos y aderezos de sus personas compiten 
con los más profanos del mundo. Y aun cantar en un coro, siendo tan fácil, no lo saben o no lo quieren hacer. Y estos que tan poco aprovechan en la Iglesia, se llevan el mejor bocado de ella, quitándolo a otras personas que fueran dignas y de la boca de los pobres. En lo cual es mucha razón que este sagrado concilio provea y quite este oprobio de Israel y tan grande abominación que está asentada en lugar santo de Dios ${ }^{50}$.

Ávila plantea recuperar para ellos la vida de comunidad (recuerda la figura de Santo Domingo en la iglesia de Osma), es decir, extender el estilo de los canónigos regulares. Puesto que le parece difícil una corrección, entiende que el mejor remedio sería establecer «un colegio cerca de la iglesia catedral en el cual, por algunos años, sean criados debajo de muy regular disciplina», con estudio y participación en la liturgia de las horas, «y darles una vida tan estrecha, que los malos la tengan por pensión tan dura, que, por no sujetarse a ella, no tomen la renta o no la procuren como la procuran $»^{51}$.

\section{d) Una inversión de valores: la vuelta a la pobreza}

La reflexión sobre el clero catedralicio conduce a Ávila a cuestionar la mentalidad según la cual «la honra» de la Iglesia se rige por los criterios vigentes en la sociedad, desviándose del sentir antiguo de la Iglesia y de los santos:

El común parecer de ahora es que conviene ser los eclesiásticos ricos, porque puedan tener sus personas y casas autorizadas con criados, mulas, atavíos y cosas semejantes. Lo cual dicen que es cosa expediente a la honra de la Iglesia y de Cristo, cuyos ministros ellos son. Mas, cierto, en esto hay dos males; uno, en este vano tratamiento; y otro, peor, en decir que esto conviene a la honra de Cristo y de su Iglesia. Porque, si verdad dicen, se sigue claro que Jesucristo no la honró, pues no fue por este camino; imo, que la deshonró, pues se trató al revés de como ellos se tratan. La honra de la Iglesia es Jesucristo; que a Él dice ella: Tu es gloria mea (Sal 3,4); y la honra de ella es celestial y desdeñarse de ser honrados con seda, y con vestidos, y con semejantes poquedades, como si quisieren ataviar el oro con cercado de lodo. La honra de los ministros de Cristo es seguir a su Señor, no solo en lo interior, sino también en lo exterior; para que así como [Él], viniendo en el mundo, fue luz que desengañó a los mundanos y les dio a entender con su palabra y ejemplo que había otra vida muy más excelente, la cual se había de desear y ganar con el desprecio de ésta, así ellos fuesen luz del mundo y sal de la tierra (Mt 5,13-14), que diesen a entender que su reino no es de este mundo, y con su ejemplo moviesen al pueblo flaco a despreciar las cosas de acá ${ }^{52}$.

50. Memorial I, n. 20, OC II, 498.

51. Ibid., 499.

52. Ibid., n. 21, 499-500. 
Sin embargo, este criterio de honra mundana quedaría deshecho si los eclesiásticos atendiesen a «lo que dice de ellos el vulgo». En efecto, pese a su poderío social, quienes se comportan según esta mentalidad «son desestimados y tenidos por profanos y juzgados por malos aun de los muy ignorantes», pues entienden que tal ostentación proviene de «raíces de soberbia en el corazón $»^{53}$. Ávila conecta esta mundanidad con el anticlericalismo popular, pues queda patente una desigualdad tan grande que levanta envidias y murmuraciones contra Dios.

Esta realidad, que se aparta del «sentido de la Iglesia y de los santos» ${ }^{54}$, requiere, para ser corregida, no solo el cambio de mentalidad, sino las medidas necesarias para una verdadera redistribución de bienes en la Iglesia. Ávila aspira a que Trento toque estos asuntos para «dar a los eclesiásticos vida sin mendicidad y riquezas», evitando así los dos extremos que hacen peligrar la virtud; una redistribución de las rentas de los beneficios en la que se tengan en cuenta también las necesidades de los colegios para la formación de clérigos y la atención a los pobres. Cuando, al final del Memorial primero, concreta sus propuestas, escribe: «Ningún beneficio haya ni capellanía que no sea bastante para dar de comer razonablemente a un sacerdote. Lo cual hecho, ninguno pueda tener más de un beneficio, ni simple, ni menos dos obispados» ${ }^{55}$.

\section{e) La vuelta a la naturaleza sacerdotal y pastoral de los ministerios}

Como he indicado anteriormente, la comprensión avilista de los ministerios en la Iglesia, en el contexto de la división entre orden y jurisdicción, supone una diferencia de lenguaje respecto a la actualidad que es necesario tener en cuenta. Así, Ávila habla del oficio sacerdotal no en un sentido global, sino estricto, orientado a la celebración de la eucaristía, y habla luego de los oficios de cura de almas, confesores y predicadores, que podemos entender como propiamente pastorales ${ }^{56}$. Sin embargo, no hay que interpretar esto sin más como una visión fragmentaria del ministerio ordenado ni tampoco como una sacerdotalización del ministerio (sin negar que esta se diera en la época). Se trata, más bien, de una reflexión que parte de la realidad de la Iglesia de su tiempo, pero alcanza, en su profundidad, un sentido unitario que proviene de la participación en el misterio de Jesucristo, Sacerdote y

53. Id.

54. Ibid., n. 22, 501.

55. Ibíd., n. 37, 507.

56. M. J. Fernández Cordero, «Jesucristo, 'fuente de nuestro sacerdocio'...», 9. 
Pastor. Adentrándonos en cómo Ávila lo contempla, es claro que acción sacerdotal y acción pastoral coinciden: «son dos dimensiones del mismo recorrido histórico de Jesús, que culminan en el mismo acontecimiento que es el misterio pascual $\rangle^{57}$.

La vuelta a este centro constituiría la clave espiritual de la reforma. Así, el oficio sacerdotal solo se renovaría con una vuelta a la oración y el sacrificio (ofrenda de sí) que le son propios ${ }^{58}$; el oficio de cura de almas, volviendo a su esencia de ayudar y enseñar, de curar, fortalecer y hermosear con virtudes del cuerpo místico de Cristo $^{59}$; el de los confesores, que es oficio de curar y hasta resucitar, requiere sobre todo caridad y ciencia, además de prudencia y paciencia ${ }^{60} ;$ y el de los predicadores, cuya presencia o ausencia es la que más determina la reforma del pueblo ${ }^{61}$, reconociendo el acto espiritual que supone la predicación, engendrar por la palabra hijos espirituales para Dios ${ }^{62}$.

Por otra parte, aunque diferenciados, la unidad última de estos ministerios les otorga una interioridad semejante: el cura de almas lleva anejo el oficio sacerdotal y debe conocer la Escritura y la moral; el confesor es pastor que ha de cuidar de su grey y orar por ella, ha de saber orientar y consolar a los penitentes como un padre ${ }^{63}$; el predicador ha de engendrar hijos espirituales con la palabra, pero sobre todo con gemidos y lágrimas, ofreciéndose a sí mismo por la vida de sus hijos. Todo, pues, converge hacia una configuración con Cristo Sacerdote y Pastor que requiere participar espiritualmente en un misterio que culmina en la ofrenda existencial de la vida.

\section{LA ÍNDOLE ESPIRITUAL DE LA REFORMA DEL CLERO DEPENDE DE SU SE- LECCIÓN Y FORMACIÓN}

El Memorial primero comienza manifestando la insuficiencia del camino por el que habitualmente se quiere lograr la reforma de la Iglesia: «hacer buenas leyes y mandar que se guarden so graves penas». Tal camino queda in-

57. Ibid., 23-24.

58. Tratado sobre el sacerdocio, n. 1-35, en: OC I, 907-939. Sobre su contenido y estructura, M. J. Fernández Cordero, Juan de Ávila..., 800-830.

59. Tratado sobre el sacerdocio, n. 36-39, 939-942.

60. Ibid., n. 40-44, 942-944.

61. Ibid., n. 45-47, 944-946. «Por experiencia se ve que el pueblo donde hay predicación de la Palabra de Dios, se diferencia de aquel donde no la hay como tierra llovida y fértil a la seca, que, en lugar de fruto, dé abrojos y espinas» (n. 45, 945).

62. La espiritualidad del predicador, en la Carta 1, OC I, 5-14, que sabemos fue escrita para Fr. Luis de Granada.

63. Plática 5. Instrucción de confesores y penitentes, n. 1, OC I, 833. 
habilitado en cuanto falta «fundamento de virtud» para cumplir esas buenas leyes, y todo se queda en una realidad caracterizada por la «mucha maldad con muchas y muy buenas leyes $\rangle^{64}$.

Estas palabras de Ávila se podrían asociar al testimonio según el cual, recordando los tiempos de su abandono del estudio del derecho en Salamanca, habría dicho: «para qué se me daban a mí las negras leyes» ${ }^{65}$; y ello podría llevar a la conclusión de que se situaba en una corriente antijuridicista o de aversión al derecho. Pero no es así; su perspectiva es, más bien, la de una visión pastoral del derecho canónico, orientada por la búsqueda de la salus animarum, en la que el cumplimiento de las leyes tiene que ver con la justicia y con la gracia (como la Ley nueva, que hace a los hombres amadores de ella, frente a la Ley vieja, que solo mandaba y castigaba al transgresor). Las leyes por sí mismas no pueden dar la solución, aunque se requieran; de ahí que Ávila la busque en la formación de los pastores ${ }^{66}$.

Puesto que «aprovecha poco mandar bien, si no hay virtud para ejecutar lo mandado ${ }^{67}$, es la virtud lo que hay que perseguir para lograr la reforma:

Si quiere, pues, el sacro concilio que se cumplan sus buenas leyes y las pasadas, tome trabajo, aunque sea grande, para hacer que los eclesiásticos sean tales, que more en ellos la gracia de la virtud de Jesucristo; lo cual alcanzado, fácilmente cumplirán lo mandado; y aun harán más por amor que la Ley manda por fuerza ${ }^{68}$.

Lo que le preocupa en este punto es la tibieza de «los mayores» respecto de «sus inferiores»; no cabe duda de que se trata de las instancias jerárquicas de la Iglesia, en las que percibe falta de ciencia y caridad para llevar adelante dicho trabajo. Es decir, de nuevo la interioridad de esta misión exige una entrega muy superior a la mera ordenación disciplinar:

Porque mandar es cosa fácil y sin caridad se puede hacer; mas llevar a cuestas flaquezas ajenas con perseverante corazón de las remediar e hacer fuerte al que era flaco, pide riqueza de caridad. Y no sé si la tienen los señores; no se

64. Memorial I, n. 1, OC II, 485.

65. Proceso de beatificación del Maestro Juan de Ávila (Ed. por J. L. Martínez Gil), Madrid 2004, 24. Se trata de la declaración de Juan de Vargas (muy vinculado al discípulo y amanuense de Ávila en Montilla, Juan de Villarás), en el Proceso de Madrid.

66. N. Álvarez de las Asturias, «Negras leyes o instrumento para la reforma: Juan de Ávila y el derecho canónico», en: J. Aranda Doncel - A. Llamas Vela (eds.), San Juan de Ávila, Doctor de la Iglesia. Actas del Congreso Internacional, Córdoba 2013, 227-239; sitúa la perspectiva pastoral avilista en la línea de Ivo de Chartres y de San Bernardo.

67. Memorial I, n. 4, OC II, 487.

68. Ibid., n. 5. 487. 
ve en doctrinar y hacer buenos a sus esclavos, sino en mandar y castigarlos; mas los padres instituyen en toda buena disciplina a sus hijos, y gastan en ello sus haciendas y personas. Y pues prelados con clérigos son como padres con hijos y no señores con esclavos, prevéanse el papa y los demás en criar a los clérigos como a hijos, con aquel cuidado que pide una dignidad tan alta como han de recibir; y entonces tendrán mucha gloria en tener hijos sabios y mucho gozo y descanso en tener hijos buenos, y gozarse ha toda la Iglesia con buenos ministros. Y hacer esto es cumplir lo que nuestro Señor dijo: Qui voluerit inter vos primus esse, erit omnium servus (Mc 10,44) ${ }^{69}$.

De nuevo encontramos explícita una inversión de valores respecto a los imperantes en la sociedad, pues, al aplicar la cita evangélica, son «los mayores» los que han de trabajar por «los menores» como los siervos para su señor, incluso como «esclavos» y «amándolos como verdaderos padres», con una entrega sacrificial como la de Cristo, que vino a servir y no a ser servido (cf. Mt 20,28).

Al llegar aquí, Ávila subraya:

Y éste es el punto principal del negocio y que toca en lo interior de él; sin lo cual todo trabajo que se tomare cerca de la reformación será de muy poco provecho, porque será, o cerca de cosas exteriores, $\mathrm{o}$, no habiendo virtud para cumplir las interiores, no dura la dicha reformación por no tener fundamento ${ }^{70}$.

Este núcleo «interior» de la reforma permite comprender que todo lo demás debe estar inspirado por este mismo espíritu. Así, la exigencia en la selección de los candidatos se refiere a la autentificación de la vocación, y de ello depende la reforma del clero: si los males que sufre la Iglesia vienen principalmente «por los pecados de los eclesiásticos», por «estar en la Iglesia hombres indignos y haber entrado por la puerta falsa», había que cerrar tal entrada $^{71}$. En los criterios de selección, «no sea preferido el más docto al más virtuoso», ni tampoco el de mayor escala social, pues «por experiencia conocen todos casi nunca haber dañado a la Iglesia el sacerdote selecto que no fuese letrado, ni rico, ni alto, y siempre le dañó mucho la malicia armada de letras y de dignidad» ${ }^{72}$. La selección se ha de fijar en «lo que es espíritu», no estimar «lo que es carne», de modo que solo entren «los buenos», pues tales se buscan «para sacerdotes y no para filósofos ni poderosos» ${ }^{73}$.

69. Ibid., n. 5, 487.

70. Ibid., n. 5, 488.

71. Ibid., n. 16, 494-495.

72. Ibid., n. 16, 495.

73. Ibid., n. 18, 496. 
Y la formación ha de mirar primero a establecer un estilo de vida en los eclesiásticos caracterizado por la virtud y el espíritu, de tal modo que esta «vida reglar y espiritual, ella misma despedirá a los malos» ${ }^{74}$. Es decir, el proceso formativo autentificaría la llamada a lo largo del tiempo, de tal modo que lo recorrerían «los virtuosos o los que trabajan en serlo». Ávila pensó en colegios específicos atendiendo a los ministerios pastorales que los educandos asumirían después: colegios para curas y confesores, donde aprendieran gramática, casos de conciencia y algo de Sagrada Escritura, y colegios para sacar «muy doctos lectores y predicadores», con un conocimiento mucho mas profundo de la Palabra de Dios y «con mayor cuidado en toda disciplina y santidad», por pensar que así lo requería la predicación (itinerante) de la Palabra, a la que vinculaba la sabiduría y el ejercicio del consejo y compañía de los obispos ${ }^{75}$.

Ya en la aplicación del concilio de Trento, su alusión a los seminarios en las Advertencias al concilio de Toledo mantiene la misma finalidad esencial y propone para formar a los que pueden ser más doctos tener alguna casa en alguna universidad ${ }^{76}$.

\section{CONCLUSIÓN}

Todo lo dicho nos lleva a concluir que la reforma avilista requiere conversión personal para impulsar procesos de cambio en las estructuras eclesiales. Es una reforma desde dentro, en la Iglesia (cf. Congar). No es sobre todo una reforma moral, jurídica o disciplinar, aunque incluya estos niveles, sino vital; «nace del espíritu, y atañe más a lo interior que a lo exterior, pues reformando aquello se asegura la reforma de esto, que es su expresión» ${ }^{77}$. Y, por todo ello, se fundamenta en la gracia, en la acción del Espíritu en el interior de la persona y de la Iglesia.

74. Ibid., n. 6, 488.

75. Ibid., n. 13-15, 492-494.

76. Advertencias al concilio de Toledo, n. 40, OC II, 682.

77. M. Navarro Sorní, «San Juan de Ávila...», 72. 


\section{BIBLIOGRAFÍA CITADA}

Aldana Valenzuela, R. «La reforma de la Iglesia en la escucha de la Palabra de Dios. Una mirada al magisterio de San Juan de Ávila», Studia Cordubensia 6 (2013) 5-144.

Antón, A. El misterio de la Iglesia. Evolución histórica de las ideas eclesiológicas, Madrid 1986, vol. I.

Congar, Y. Verdadera y falsa reforma en la Iglesia, Salamanca 2014.

Duval, A. "Quelques idées du bienheureux Jean d'Avila sur le ministère pastoral et la formation du clergé», La Vie Spirituelle. Supplément (1948) 121-153.

Fernández Collado, A. «San Juan de Ávila y la reforma del clero. Memoriales y advertencias a los concilios de Trento y provincial de Toledo», Scripta Fulgentina 57-58 (2019) 283-295.

Fernández Collado, A. Concilios Toledanos postridentinos. Estudio y edición Toledo 1996.

Fernández Collado, A. «El Concilio Provincial Toledano de 1565», Anthologica Anпиa, 42 (1995) 425-613.

Fernández Cordero, M. J. Juan de Ávila (1499?-1569). Tiempo, vida y espiritualidad, Madrid 2017.

Fernández Cordero, M. J. «Jesucristo, «fuente de nuestro sacerdocio». Claves para la comprensión del pensamiento de Juan de Ávila sobre el ministerio sacerdotal», Studia Cordubensia 11 (2018) 5-24.

Godino Alarcón, J. R. «El marco histórico del ministerio presbiteral en el siglo XVI y la reforma de la Iglesia en los Memoriales de Ávila», en: F. J. Martínez Rojas (coord..), El presbitero secular en el siglo XXI a la luz del magisterio de San Juan de Ávila. Actas del Congreso Internacional, Jaén 2020, 89-102.

Huerga, A. «La reforma de la «Santa Madre Iglesia» según el Maestro Juan de Ávila», Communio 3 (1970) 175-225.

López Santidrián, S. «Reformador», en: M. E. González Rodríguez (ed.), San Juan de Ávila, doctor: magisterio vivo, Madrid 2013, 57-100.

Navarro, J. La reforma de la Iglesia en los escritos del Maestro Ávila. Su enfoque teológico, Granada 1964.

Navarro Sorní, M. «San Juan de Ávila y la reforma de la Iglesia», en: N. Álvarez de las Asturias (ed.), San Juan de Ávila, Doctor de la Iglesia, Madrid 2013, 49-84.

Pérez García, R. M. «El tema de la crítica al clero en la obra de Francisco de Osuna en el contexto del pensamiento católico reformista pretriden- 
tino», en: E. Soria Mesa - A. J. Díaz Rodríguez (eds.), Iglesia, poder y fortuna. Clero y movilidad social en la España moderna, Granada 2012, 139-189.

Río Martín, J. del, Santidad y pecado en la Iglesia. Hacia una eclesiología de San Juan de Ávila, Madrid 2015.

Schatz, K. Los concilios ecuménicos. Encrucijadas en la historia de la Iglesia, Madrid 1999.

Tellechea Idígoras, J. I., «San Juan de Ávila y la reforma de la Iglesia», en: El Maestro Ávila. Actas del Congreso Internacional, Madrid 27-30 noviembre 2000, Madrid 2002, 47-75. 